\title{
Development, Characterization, and Testing of a SiC-Based Material for Flow Channel Inserts in High-Temperature DCLL Blankets
}

\author{
Carlota Soto®, Carmen García-Rosales, Jon Echeberria, Ernests Platacis, Andrejs Shisko, \\ Faina Muktepavela, Teresa Hernández, and Marta Malo Huertac
}

\begin{abstract}
Flow channel inserts (FCIs) are the key elements in the high-temperature dual-coolant lead-lithium blanket, since in this concept the flowing $\mathrm{PbLi}$ reaches temperatures near $700{ }^{\circ} \mathrm{C}$ and FCIs should provide the necessary thermal and electrical insulations to assure a safe blanket performance. In this paper, the use of a $\mathrm{SiC}$ sandwich material for FCIs consisting of a porous $\mathrm{SiC}$ core covered by a dense chemical vapor deposition-SiC layer is studied. A fabrication procedure for porous $\mathrm{SiC}$ is proposed and the resulting materials are characterized in terms of thermal and electrical conductivities (the latter before and after being subjected to ionizing radiation) and flexural strength. $\mathrm{SiC}$ materials with a wide range of porosities are produced; in addition, preliminary results using an alternative route based on the gel-casting technique are also presented, including the fabrication of hollow samples to be part of future lab-scale FCI prototypes. Finally, to study the corrosion resistance of the material in hot $\mathrm{PbLi}$, corrosion tests under static $\mathrm{PbLi}$ at $700{ }^{\circ} \mathrm{C}$ and under flowing PbLi at $\sim 10 \mathrm{~cm} / \mathrm{s}$ and $550{ }^{\circ} \mathrm{C}$, with and without a 1.8-2T magnetic field, were performed to materials coated with a $200-400-\mu$ m-thick dense $\mathrm{SiC}$ layer, obtaining promising results.
\end{abstract}

Index Terms - Corrosion by PbLi, dual-coolant lead- lithium (DCLL) blanket, electrical conductivity, flow channel insert (FCI), porous SiC, thermal conductivity.

\section{INTRODUCTION}

The dual-coolant lead-lithium (DCLL) breeding blanket is being investigated as a candidate for DEMO, where an important requirement will be to provide the highest possible efficiency in converting the energy coming out from the burning plasma to electricity while achieving tritium selfsufficiency [1]. The DCLL principle is based on the use of an eutectic PbLi alloy in liquid state acting as breeder and coolant, flowing through long channels while heating up to

C. Soto, C. García-Rosales, and J. Echeberria are with the Department of Materials and Manufacturing, Ceit-IK4 Technology Center, 20018 San Sebastian, Spain, and also with the University of Navarra, 20018 San Sebastian, Spain (e-mail: csoto@ceit.es).

E. Platacis, A. Shisko, and F. Muktepavela are with the Institute of Solid State Physics, University of Latvia, 2169 Salaspils, Latvia.

T. Hernández and M. M. Huertac are with CIEMAT, National Fusion Laboratory, 28040 Madrid, Spain. high temperatures. A low-temperature version of the DCLL blanket is currently being designed at CIEMAT [2], where the $\mathrm{PbLi}$ operates at temperatures lower than $\sim 550{ }^{\circ} \mathrm{C}$; the potentiality to elevate the $\mathrm{PbLi}$ operating temperature up to $\sim 700{ }^{\circ} \mathrm{C}$ with the consequent increase of efficiency in the power conversion system makes the DCLL an interesting concept for the future [1], although high-temperature materials must be developed and tested to face this concept.

In the DCLL blanket, the liquid PbLi will be in direct contact with the blanket structure, which is expected to be made of a reduced activation ferritic martensitic (RAFM) steel like EUROFER; to assure the corrosion stability against hot $\mathrm{PbLi}$ it is thus crucial to ensure a reliable operation of all materials in direct contact with it. The corrosion behavior against PbLi of RAFM steels is strongly dependent on the temperature and the flow characteristics of the PbLi [3], [4]. Although the experimental data regarding the corrosion rate of RAFM in flowing PbLi differ in a wide range, corrosion issues are supposed to appear at temperatures near $450-550{ }^{\circ} \mathrm{C}$; besides, the presence of a magnetic field may affect severely the corrosion rate [4]-[6]. Therefore, to assure that the steel is maintained at a temperature at which severe corrosion issues are avoided, in a high-temperature DCLL, the PbLi should present a sufficient thermal insulation with respect to the blanket structure. In addition, to reduce magnetohydrodynamic (MHD) effects that may affect the flow velocity and the heat transfer, the $\mathrm{PbLi}$ flow should be also electrically decoupled from the conducting steel. Studies and experimental tests under relevant conditions must be performed to assure the correct performance of all components.

The blanket components responsible for the thermal and electrical insulation are key element in the DCLL design, especially in the high-temperature concept, and are called flow channel inserts (FCIs). FCIs are typically designed as hollow square channels of a few millimeter thick, containing the hot flowing $\mathrm{PbLi}$ and being separated from the RAFM steel wall by a thin gap also filled with $\mathrm{PbLi}$. In the frame-work of the lowtemperature DCLL design, FCI prototypes made of a steelalumina-steel sandwich material are being tested [2]. In a hightemperature approach, however, additional challenges must be overcome regarding the FCI material, especially concerning the corrosion phenomena and the ther-mal stresses that will be present in the channels due to the 
considerably high thermal gradient across its walls. For these reasons, silicon carbide $(\mathrm{SiC})$ is considered as a candidate for FCIs in a more advanced high-temperature DCLL approach, due to its good behavior in high radiation environments, its chemical stability under $\mathrm{PbLi}$, and its high mechanical strength. However, the relatively high thermal and electrical conductivities of this ceramic require the development of a low-conductivity $\mathrm{SiC}$ material. The insulation requirements of FCIs depend on their design parameters, such as its projected thickness and shape, as well as on other aspects like the PbLi flow velocity profile; all these dependencies are being studied and discussed in several works. In the analysis of the technical challenges on the pathway to DEMO made by Abdou et al [7], the requirement for effective FCI performance in terms of thermal conductivity is considered in the range $1-5 \mathrm{~W} /(\mathrm{m} \cdot \mathrm{K})$ and in the electrical conductivity of $1-10 \mathrm{~S} / \mathrm{m}$; in the review of the DCLL status made by Smolentsev et al. [8], the most restrictive goal regarding the FCIs of the inboard blanket is to achieve a thermal conductivity of $1-2 \mathrm{~W} /(\mathrm{m} \cdot \mathrm{K})$ and an electrical conductivity of about $1 \mathrm{~S} / \mathrm{m}$. Besides, recent studies like the one presented by Chen et al. [9] show the dependence between the FCI design and the MHD effects or the heat transfer profile, while the thickness of FCIs has a significant influence. In this paper [9], the authors suggest a 5-mm FCI, assigning them a thermal conductivity of $8 \mathrm{~W} /(\mathrm{m} \cdot \mathrm{K})$ and a considerably low electrical conductivity of $0.0001 \mathrm{~S} / \mathrm{m}$. The results pointed out by the different studies are consistent with

a previous study presented by Soto et al. [10], where a $\sim 5-$ $\mathrm{mm}$ FCI with a thermal conductivity near $7 \mathrm{~W} / \mathrm{m} \cdot \mathrm{K}$ is suggested as a possible option. Essentially, it can be concluded that research and development efforts must be done to develop a low conductivity, high resistant $\mathrm{SiC}$ material with a wide enough design window to be consistent with the blanket requirements. This material has to be characterized under relevant conditions, and its manufacturing possibilities have to be taken into account.

Together with the development of $\mathrm{SiC} / \mathrm{SiC}$ composites [11], other potential candidates for FCIs are $\mathrm{SiC}$-sandwich materi-als, based in a core of porous $\mathrm{SiC}$ covered by a dense $\mathrm{SiC}$ coat-ing typically produced by chemical vapor deposition (CVD). Following this concept, foam-based SiC FCI prototypes have been produced by Ultramet, tested in UCLA using the MaPLE facility and analyzed at CIEMAT [12]-[14]; in this material, a highly porous $\mathrm{SiC}$ foam infiltrated with silica aerogel is covered by a CVD-SiC coating of about $1 \mathrm{~mm}$ thickness.

In this paper, a different $\mathrm{SiC}$-sandwich material is presented, based on an alternative production method of porous $\mathrm{SiC}$. Following this method, materials with a wide range of porosi-ties and hence of properties can be produced; the fabrication process, as well as the properties of the material obtained, is shown in Section II. Porous $\mathrm{SiC}$ samples produced by this method have been also coated with a dense CVD-SiC layer with thicknesses between $\sim 200-400 \mu \mathrm{m}$; such a thickness has been chosen to study if it is enough to provide protection against $\mathrm{PbLi}$ corrosion while reducing the high mechanical stresses that seem to concentrate in this dense layer, according to the results presented in the previous work mentioned before [10]. The coating process has been performed at Archer
Technicoat Ltd., U.K. To determine the insulating properties of the material, its thermal and electrical conductivities have been studied; in the latter case, measurements have been also performed after subjecting the samples to ionizing radiation, using a $2 \mathrm{MeV}$ Van de Graaff electron accelerator at CIEMAT. These results are also presented in Section II. Furthermore, to study the viability of a method which allows the fabrication of hollow samples of the required size and shape for FCIs, an adaptation of the fabrication procedure to the gel-casting technique is being studied; preliminary results obtained by this method are presented in Section III.

To characterize the material's behavior against hot $\mathrm{PbLi}$ corrosion, two different experiments have been conducted. First, porous samples coated with a $\sim 200-\mu \mathrm{m}$ CVD-SiC layer were tested under static $\mathrm{PbLi}$ at $700{ }^{\circ} \mathrm{C}$ for $1000 \mathrm{~h}$ [15]. A second corrosion experiment has been recently performed, testing a new batch of coated samples under flowing $\mathrm{PbLi}$ at $\sim 10 \mathrm{~cm} / \mathrm{s}$ and $550{ }^{\circ} \mathrm{C}$ for $850 \mathrm{~h}$; in order to study the possible influence of the presence of a magnetic field in the corrosion phenomena, some samples were subjected to a $1.8-2 \mathrm{~T}$ magnetic field during the experiment. The results of these corrosion tests are presented in Section IV. The mentioned experiments have been performed using lab-scale flat samples; in the future, further tests will be performed with hollow lab-size FCI prototypes.

\section{Porous SiC Production}

\section{A. Experimental Procedure}

The proposed production method of porous $\mathrm{SiC}$ is based on the sacrificial template technique, widely used in the fabrication of porous ceramics [16]. In this procedure, the material is obtained from a powder mixture to which a sacrificial phase is added, being this phase later removed leaving pores in the structure.

In this paper, $\mathrm{SiC}$ powder (Superior Graphite, $0.3 \mu \mathrm{m}$ ) together with 1.5 wt.\% $\mathrm{Al}_{2} \mathrm{O}_{3}(0.4 \mu \mathrm{m})$ and 1 wt.\% $\mathrm{Y}_{2} \mathrm{O} 3(1$ $\mu \mathrm{m})$ powders were used as initial powders, the last two acting as sintering additives. Spherical graphite particles derived from mesocarbon microbeads (MCMB, $15 \mu \mathrm{m}$ ) were also added to the mixture as sacrificial phase in quantities ranging from 0 to $22 \mathrm{wt} . \%$. The sintering additives together with the $\mathrm{SiC}$ powder and $3 \mathrm{wt} \%$ of an aqueous polymer as binder agent were mixed in ethanol for $18 \mathrm{~h}$, being the MCMB added afterward to the solution and mixed for another $30 \mathrm{~min}$. With the resulting blend, samples with the required geometries were produced by uniaxial pressing at $100 \mathrm{MPa}$. The green compacts were then sintered at $1900^{\circ} \mathrm{C}$ for $30 \mathrm{~min}$. In order to burn out the carbonaceous sacrificial phase, the sintered samples were subjected to an oxidation treatment at $700{ }^{\circ} \mathrm{C}$ for $10 \mathrm{~h}$.

The porosity of the resulting samples was calculated from the ratio of its geometrical and theoretical densities, the latter one being determined by the rule of mixtures. Microstruc-ture was studied by field emission gun scanning electron microscopy (FESEM) and energy dispersive X-ray spec-troscopy (EDS). Thermal conductivity as a function of temper-ature was determined from the specific heat capacity obtained from [17], density and thermal diffusivity of the samples 


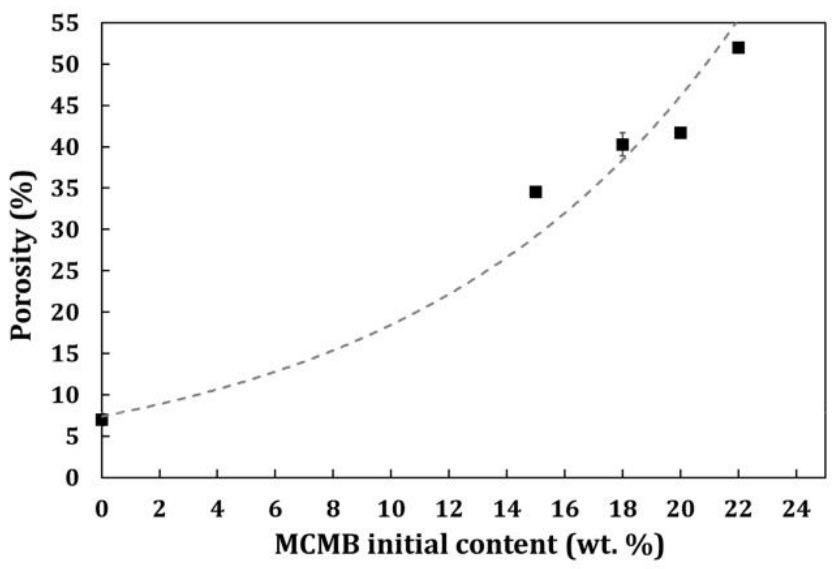

Fig. 1. Porosity of the final material as a function of its initial amount of sacrificial phase (error bars are showed only for deviations $\geq 1 \%$ ).

measured by the laser flash method. Electrical conductivity measurements were performed before and after irradiation with $1.8 \mathrm{MeV}$ electrons up to $140 \mathrm{MGy}\left(2 \cdot 10^{-5} \mathrm{dpa}\right)$. Flexural strength was determined at room temperature by three-point bending tests using four samples for each condition.

\section{B. Results and Characterization}

In Fig. 1, the final porosity of the samples as a function of its initial amount of MCMB (carbonaceous sacrificial phase) is shown for five different compositions $(15 \%, 18 \%, 20 \%$, and $22 \%$ of initial MCMB, along with the material fabricated without MCMB as reference). The final porosity increases with increasing sacrificial phase content, being the sintering process less effective in the samples with high MCMB content; in this material, the porosity increases in a more severe way, showing rather an exponential relationship with the amount of sacrificial phase.

The microstructure of materials with $35 \%, 40 \%$, and $55 \%$ porosity is shown in Fig. 2(a). The spherical pores are formed by burning out the sacrificial phase; a reduction of the sintering grade with increasing MCMB content can be observed. This effect causes residual porosity in the $\mathrm{SiC}$ matrix, detrimental to the mechanical strength. In Fig. 2(b), details of the microstructure of the pores and of the surrounding SiC matrix can be seen in a sample produced with $18 \%$ initial MCMB, resulting in a final porosity near $40 \%$.

In Fig. 3, the thermal conductivity as a function of temperature of samples with different porosities $(6 \%, 36 \%$, and $43 \%$ ) can be seen. As expected, the thermal conductivity decreases with temperature and with porosity. As the planned operation temperature of FCIs in the high-temperature DCLL is near $700{ }^{\circ} \mathrm{C}$, the thermal conductivity at this temperature of $\mathrm{SiC}$ samples with different porosities is shown in Fig. 4. The thermal conductivity of the material decreases exponentially with porosity, being the most interesting materials for FCIs in terms of thermal insulation those with porosities above $\sim 40 \%$, as they correspond to the required thermal conductivity of $<10$ $\mathrm{W} /(\mathrm{m} \cdot \mathrm{K})$ at $700{ }^{\circ} \mathrm{C}$ determined in [10].

The electrical conductivity versus the inverse of temperature of three different $\mathrm{SiC}$ materials can be seen in Fig. 5. Two porous samples with $34 \%$ and $50 \%$ porosity were measured;
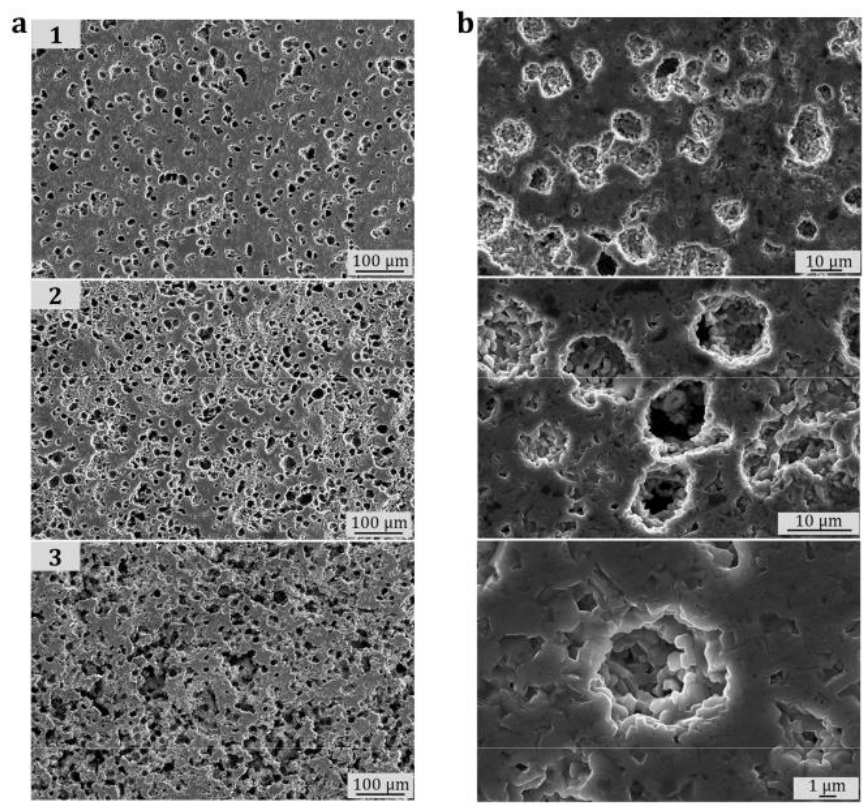

Fig. 2. (a) Low magnification FESEM micrographs of samples produced with: 1) $15 \%$ initial MCMB (final porosity 35\%); 2) $18 \%$ initial MCMB (final porosity 40\%); and 3) $22 \%$ initial MCMB (final porosity 52\%). (b) Microstructure of the pores in a $40 \%$ porous sample.

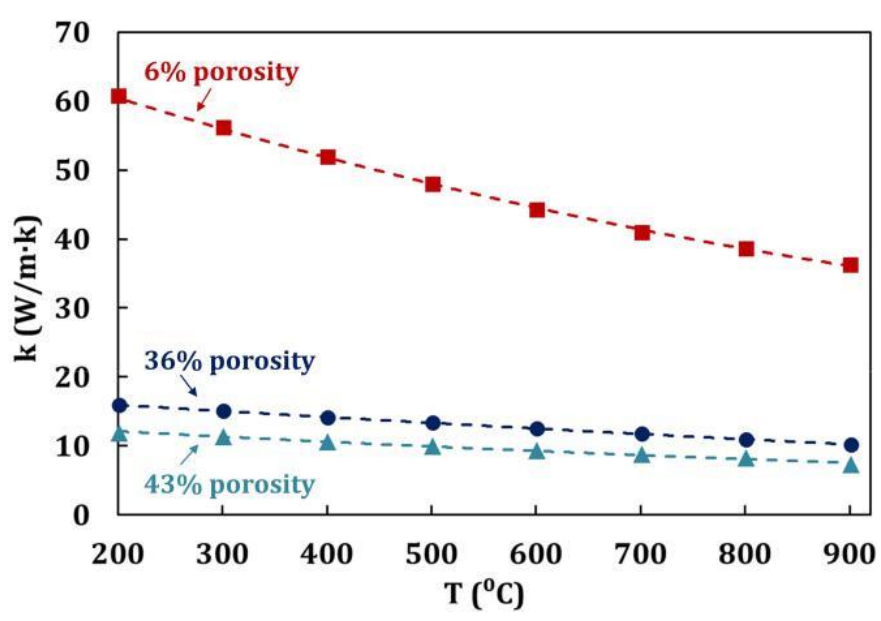

Fig. 3. Thermal conductivity as a function of temperature of samples with different porosities $(6 \%, 36 \%$, and $43 \%)$.

also, the electrical conductivity of a SiC-sandwich material, whose microstructure can be seen at Fig. 6, is presented. This sandwich sample consists of a porous core of $34 \%$ porosity and $\sim 2.5 \mathrm{~mm}$ thickness covered with a dense CVD-SiC coating of $\sim 230-300 \mu \mathrm{m}$ thickness; the sides of this sample remain uncoated to measure the through thickness conductivity. The thickness of the other two measured porous samples (without coating) was $2.5 \mathrm{~mm}$ as well. The conductivity values of the samples after electron radiation are also shown; the coated sample and those with a $34 \%$ porous core were subjected to a dose of $144 \mathrm{MGy}$, while $23 \mathrm{MGy}$ were applied to the $50 \%$ porous sample. The values of the electrical conductivity of each sample at the highest temperature tested, $550{ }^{\circ} \mathrm{C}$, are shown in Table I.

As can be seen, porosity has a great influence on the electrical conductivity, with values several orders of magnitude 


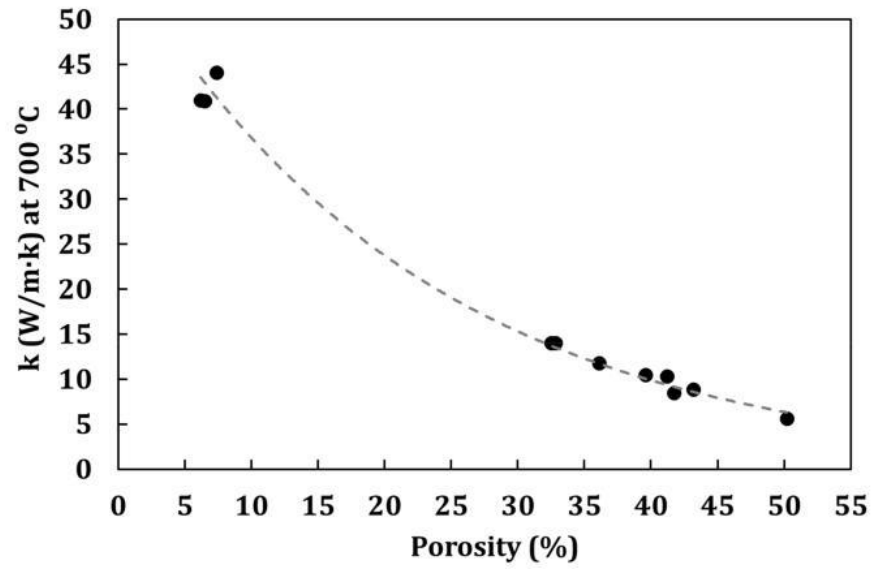

Fig. 4. Thermal conductivity at $700{ }^{\circ} \mathrm{C}$ as a function of porosity of $\mathrm{SiC}$ materials with different porosities.

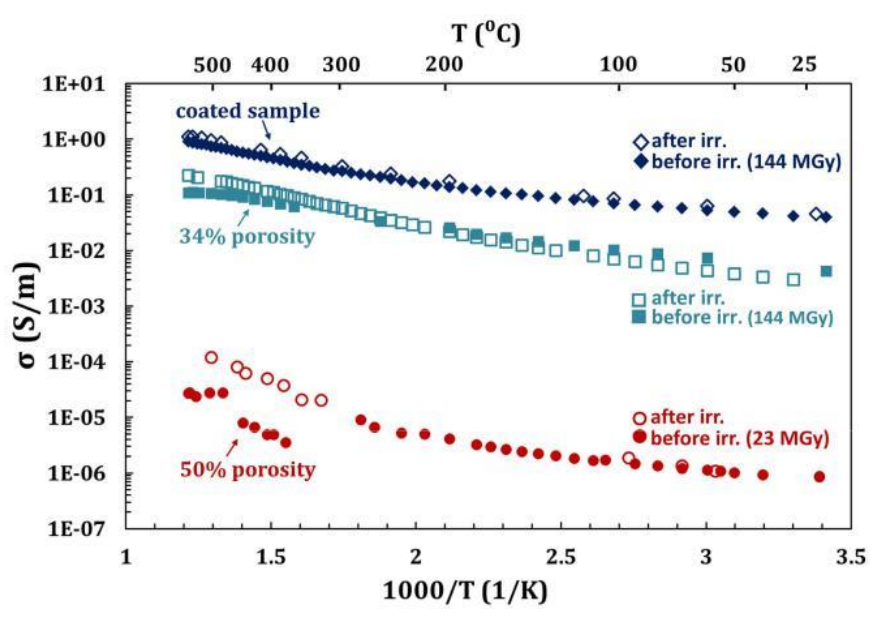

Fig. 5. Electrical conductivity versus the inverse of temperature of three different samples, before and after irradiation with $1.8 \mathrm{MeV}$ electrons. Two porous samples (with $34 \%$ and $50 \%$ porosity) and a coated $\mathrm{SiC}$-sandwich sample (formed by a porous core of $34 \%$ porosity covered by a dense CVD$\mathrm{SiC}$ layer of $230-300 \mu \mathrm{m}$ thick) are shown.
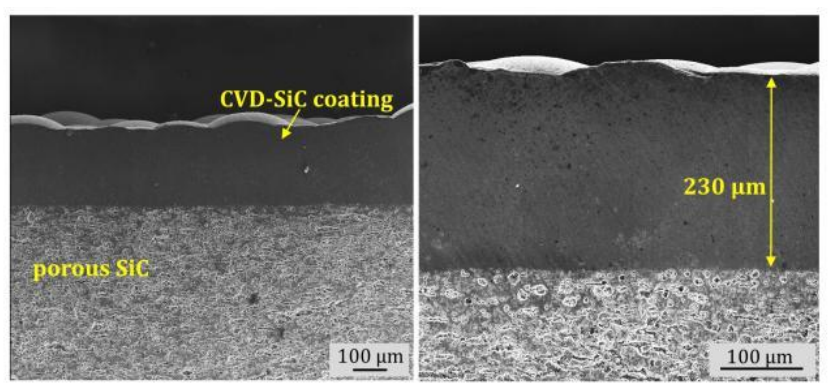

Fig. 6. FESEM micrographs of the coated sample whose electrical conductivity are shown in Fig. 5 and Table I. The dense coating covered the top and bottom of the sample (the sides remain uncoated to measure the conductivity through the thickness, avoiding short-circuits) having a thickness between 230-300 $\mu \mathrm{m}$.

higher in the $34 \%$ porous sample compared to the $50 \%$ one. The electrical conductivity of the coated material with a $34 \%$ porous core is also higher than the one of the $34 \%$ uncoated porous material, although the width of the porous layers of both materials was the same. Similar conductivities would be
TABLE I

Electrical Conductivities at $550^{\circ} \mathrm{C}$ Before AND AFTER IRRADIATION
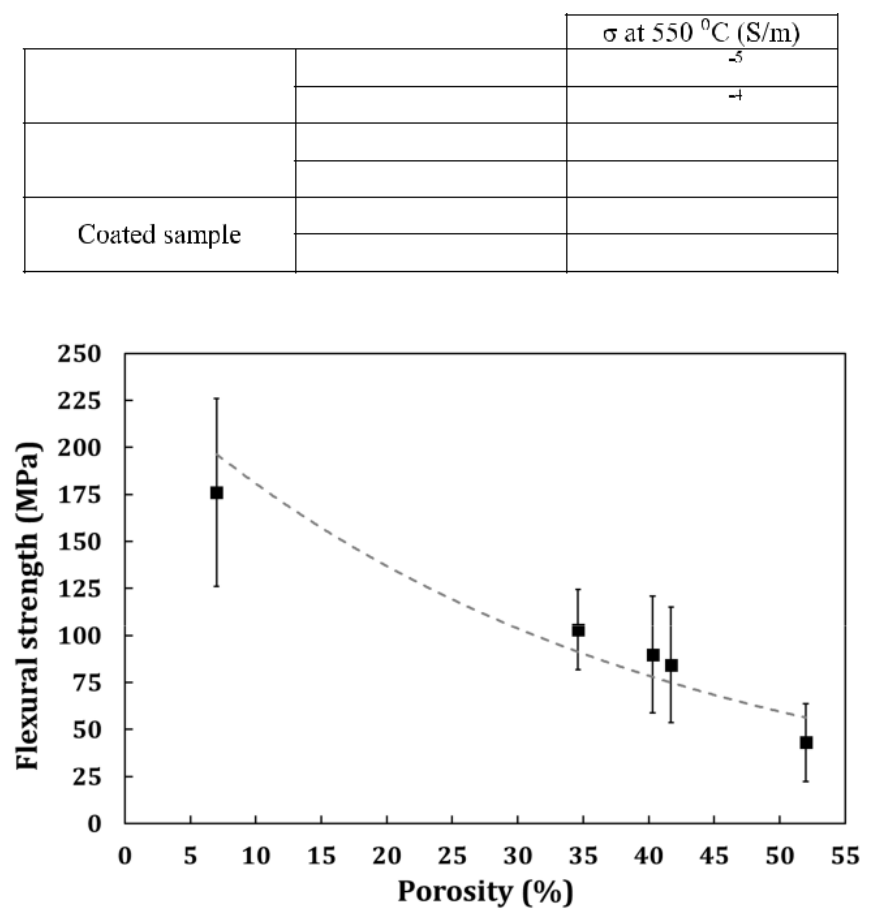

Fig. 7. Flexural strength versus porosity.

expected, taking into account that the electrical conductivity of the dense $\mathrm{SiC}$ is significantly larger than the one of the porous $\mathrm{SiC}$, which together with the reduced thickness of the coating should have small impact on the overall through thickness conductivity of the sandwich material. This unexpected result may indicate that changes occur in the porous $\mathrm{SiC}$ during the CVD treatment, inducing an increase in its electrical conductivity; this effect should be confirmed with further measurements. Regarding the influence of ionizing radiation, an increase in the electrical conductivity after irradiation is observed in all samples; nevertheless, the greatest value measured is near $1 \mathrm{~S} / \mathrm{m}$, which would fit the electrical insulation requirements.

Finally, the flexural strength as a function of the porosity can be seen in Fig. 7. As expected and introduced before, the strength decreases considerably as the porosity increases, even though the important dispersions of the measured values prevent from drawing clear conclusions. Obtaining different values of flexural strength in samples with the same composition is attributed to the presence of defects like cracks; the uniaxial pressing step contributes considerably to their appearance.

The highest dispersion was obtained in the samples pressed without sacrificial phase, which are those presenting the high-est difficulties in the compaction step due to the absence of the lubricant effect provided by the presence of graphite. The results of the mentioned previous work [10], where the distribution of the stresses caused by the thermal gradient across the FCI were studied, showed that, in a SiC-sandwich FCI like the one proposed, the highest stresses would appear in the dense coating, being the stresses supported by the porous 
core one order of magnitude lower. According to this paper, the flexural strength of the porous materials tested would be enough to support the stresses present in the core of the FCI; nevertheless, further work should be done in order to assure the production of a material free of defects, being also desirable to increase the strength of the highly porous materials to assure a safe operation.

\section{Production of Porous SiC by the Gel-Casting Technique: Preliminary Results}

The consolidation techniques commonly used in powder metallurgy imply limitations, like the relatively reduced size of the samples that can be manufactured; also, techniques such as uniaxial pressing can easily lead to the presence of defects like cracks in the samples, being this, especially true in the manufacturing of hard, brittle ceramics such as SiC. These problems added up to its hard machinability once sintered and the impossibility to manufacture it in green state due to the poor density of the green samples produced by pressing has led to an increased interest in the development of new methods for producing high-quality green ceramics, avoiding the pressing step. In the case of the production of FCIs, where the fabrication of complex shapes with a relatively large size will be needed, these alternative methods are especially interesting, as they could allow the manufacturing of samples with no limitations regarding size or geometry.

One of the promising methods is gel casting, which is based on the dispersion of the initial ceramic powders in an aqueous monomer solution to form a slurry, that is, subsequently gelled inside a mold. After unmolding and eliminating the aqueous medium by drying the sample, the result is a material with homogenous composition and density, containing a certain amount of polymer similar to the amount of binder that is commonly used in pressed ceramics [18]. The principal advantages of this method are its reduced cost, the high strength of the produced green samples, and its capability for industrial implementation, being possible to use it for almost all sizes allowing complex geometries. However, key aspects of the process must be well optimized to take full advantage of the method, like the use of high solid content suspensions with an adequately low viscosity, to properly eliminate the trapped air of the suspension before gelation, or to successfully control the dying step avoiding internal stresses in the part; these aspects, among others, are well summarized in [19].

In order to produce simple hollow square FCI proto-types, first in lab scale, with the possibility of increasing their size or vary their shape in the future, an adapta-tion of the procedure presented in Section II incorporating the gel-casting method for the porous $\mathrm{SiC}$ production is being currently studied. The first hollow samples, together with flat samples of different geometries, have been pro-duced by using acrylamide (AM) as the main monomer and $\mathrm{N}, \mathrm{N}$,-methylenebisacrylamide (MBAM) as the cross linker.

A powder mixture containing $\mathrm{SiC}$ powder, 20 wt.\% of MCMB and 2.5 wt. $\%$ of sintering additives $\left(\mathrm{Al}_{2} \mathrm{O}_{3}\right.$ and $\mathrm{Y}_{2} \mathrm{O}_{3}$ in a 3:2 ratio) was added to a premix of the monomers in water (the quantities used were $10 \mathrm{wt} . \%$ of AM and $5 \mathrm{wt} . \%$ of MBAM with respect to the amount of water). To trigger the

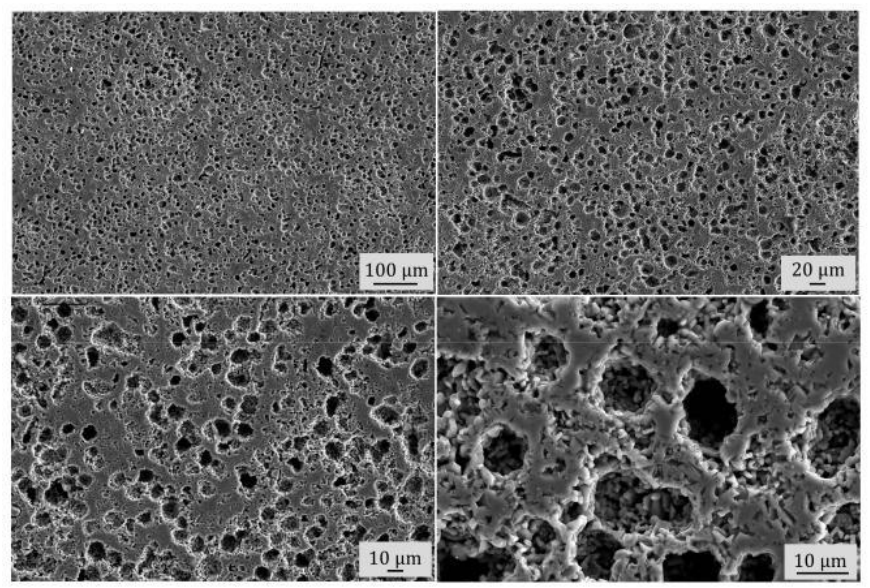

Fig. 8. FESEM micrographs of the material produced by the gel-casting method (final material; after sintering and oxidation).

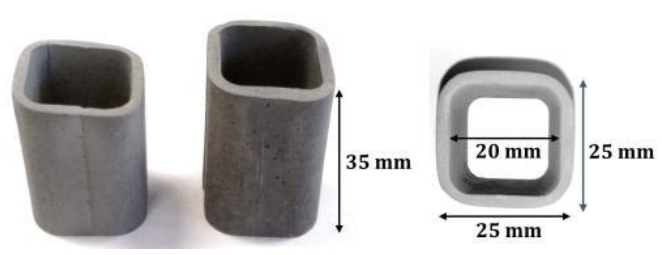

Fig. 9. Hollow porous $\mathrm{SiC}$ channels produced by the gel-casting method (final material; after sintering and oxidation).

TABLE II

Properties of the Material Produced by Gel Casting

\begin{tabular}{|c|c|c|}
\hline $\begin{array}{c}\text { Initial MCMB } \\
\text { content (wt.\%) }\end{array}$ & $\begin{array}{c}\text { Final porosity } \\
\text { (\%) }\end{array}$ & (MPa) \\
\hline 20 & 44 & $79=11$ \\
\hline
\end{tabular}

gelation reaction, N,N,N,N-tetramethylethylenediamine was used as a catalyst, together with a $5 \mathrm{wt} . \%$ aqueous solution of ammonium peroxydisulfate as initiator. The slurries were subjected to vacuum during a few seconds to remove the air trapped in the suspension, and then casted; when the gelation was completed, samples were unmolded and dried at room temperature. The next steps of the process, i.e., sintering and oxidation, were performed in the same way as in the traditional route previously presented.

The porosity and the flexural strength of the final material (using in the powder mixture a solid content of 42 vol.\%) are presented in Table II, while its microstructure can be seen in Fig. 8. The thermal conductivity of the material, which depends mainly on the amount of porosity, can be deduced from the relationship of Fig. $4[\sim 8 \mathrm{~W} /(\mathrm{m} \cdot \mathrm{K})]$. In Fig. 9, hollow square samples produced to become the core of future $\mathrm{SiC}$-sandwich lab-size FCI prototypes are shown. The properties obtained in this gel-casted material are quite similar to those of the uniaxially pressed one with the same amount of initial MCMB ( $42 \%$ porosity with a strength of $84 \pm 31 \mathrm{MPa}$ in the pressed samples versus the $44 \%$ and $79 \pm 11 \mathrm{MPa}$ obtained in the gel-casted ones). No cracks were detected in the gel-casted samples; however, additional pores of a greater 


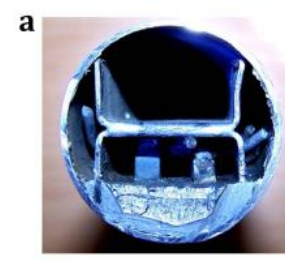

b

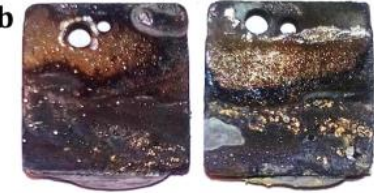

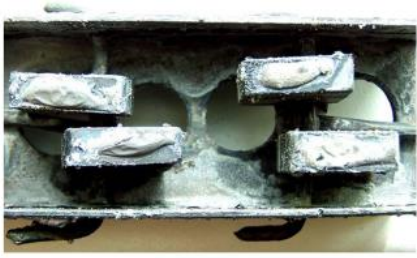

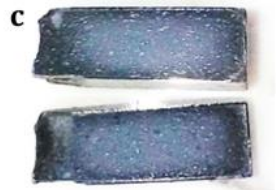

Fig. 10. Samples after the corrosion experiment under static PbLi. (a) In the experiment assembly. (b) Aspect of two samples, with PbLi adhered to the surface. (c) Cross sections of cut samples, where the inner porous $\mathrm{SiC}$ can be seen.

size than desired $(\sim 100 \mu \mathrm{m})$ were observed, caused by the trapped air not adequately removed in the degassing step. The additional porosity measured in this samples is attributed to the presence of these undesired pores, whose relatively large size deteriorate the flexural strength; the deairing process will be optimized in the future to avoid this effect. Other important elements for the optimum performance of the gel-casting method, such as the use of an adequate amount of dispersant to permit high solid contents while maintaining a low viscosity, is also still not incorporated to the process used in this paper, so that there is a large margin for improvement of the final properties of the material.

These first results show that the gel-casting technique is a promising method for the fabrication of ceramic FCIs, being possible to be used in the fabrication of more complex shapes by the design of proper molds.

\section{CORROSION EXPERIMENTS}

A crucial issue in the DCLL and FCIs design, especially regarding the high-temperature concept, is to test the materials that will be directly in contact with the hot flowing PbLi to assure that no corrosion phenomena would be altering the performance of the components. To characterize the behavior of the produced $\mathrm{SiC}$ under hot $\mathrm{PbLi}$, corrosion experiments under relevant conditions have been performed at the Institute of Physics, University of Latvia (IPUL) with lab-scale flat samples, consisting of a porous $\mathrm{SiC}$ core (fabricated by the traditional route including uniaxial pressing) covered by a CVD-SiC dense coating. New experiments with lab-size hollow FCI prototypes are in preparation.

\section{A. Test Under Static PbLi}

For the first corrosion experiment, $14 \times 14 \times 5 \mathrm{~mm}^{3}$ porous $\mathrm{SiC}$ samples with a porosity around $50 \%$ were covered with a dense CVD-SiC coating of $\sim 200 \mu \mathrm{m}$ thickness. Six samples were tested, being partially immersed in static $\mathrm{PbLi}$ at $700{ }^{\circ} \mathrm{C}$ for $1000 \mathrm{~h}$; photographs of some of the samples after finishing the test are shown in Fig. 10.

After the experiment, samples were cut and its inside was studied by FESEM, EDS, and X-ray diffraction. No lead was detected inside them and no significant reduction of

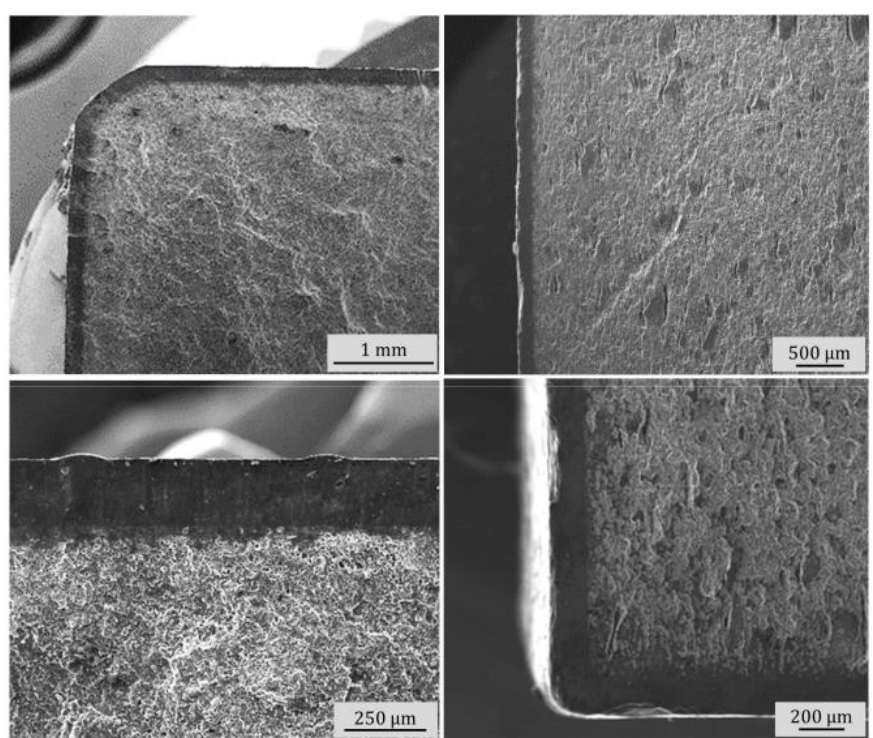

Fig. 11. Cross-sectional FESEM micrographs of the inside of samples after the corrosion experiment under static PbLi.

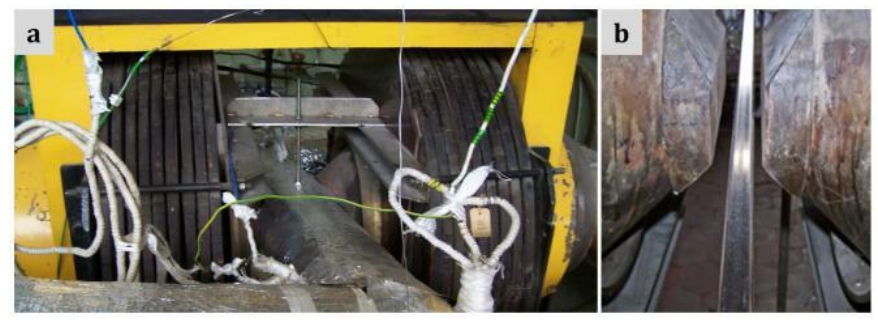

Fig. 12. (a) Experimental setup at the PbLi loop of IPUL. (b) Test channel installed between the magnet poles.

the thickness of the dense CVD-SiC coating was found (as can be observed in the micrographs showed in Fig. 10), although some damages of the dense coating occurred during dismantling the samples after the experiment. Details of these results can be found in [15].

\section{B. Test Under Flowing PbLi}

For this second experiment, a new batch of porous $\mathrm{SiC}$ samples with porosities near $40 \%$ was coated with a CVD-SiC layer. In this case, the thickness of the coating varied from $\sim 200$ to $400 \mu \mathrm{m}$, due to inaccuracies in the CVD procedure; these problems should be solved to assure the greatest possible accuracy in the thickness of the coating in the future processes. In this experiment, 11 samples were tested; eight of them were subjected to a 1.8-2 $\mathrm{T}$ magnetic field throughout the test, while three remained outside the magnetic influence as control samples. The PbLi was flowing at $\sim 10 \mathrm{~cm} / \mathrm{s}$ and $550{ }^{\circ} \mathrm{C}$, being the duration of the experiment $850 \mathrm{~h}$. A of the experimental setup at the PbLi loop of IPUL can be seen in Fig. 12; the samples subjected to the influence of the magnetic field were located in the gap between the magnetic poles to assure a completely uniform field.

Photographs of the samples after the test can be seen in Fig. 13. Surface damages were detected in two samples (marked with $*$ in Fig. 13), consisting of a partial detachment of the dense layer that occurred during the dismantling of 


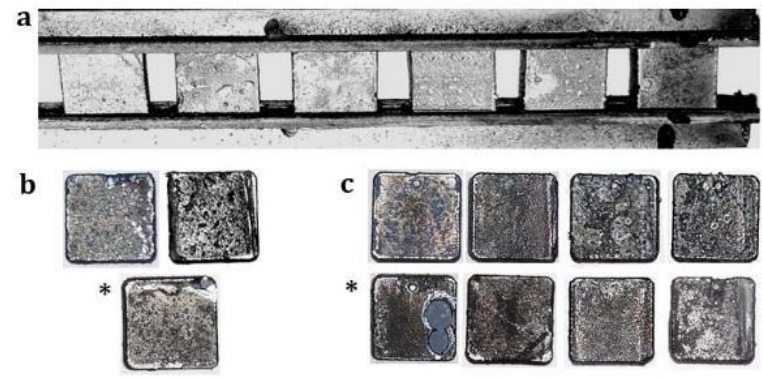

Fig. 13. Samples after the corrosion test under flowing PbLi. (a) In the experiment assembly. (b) Samples outside the magnetic field. (c) Samples subjected to the magnetic field. Samples marked with $*$ presented damages in the surface.

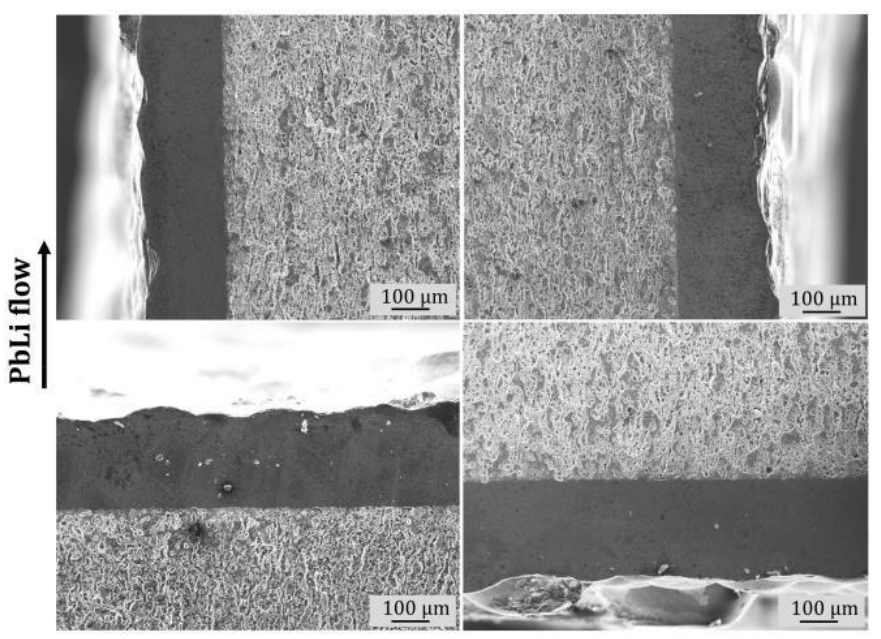

Fig. 14. Cross-sectional FESEM micrographs of the inside of a sample after the corrosion test under flowing $\mathrm{PbLi}$; sample located outside the magnetic field, with a $\sim 250-\mu \mathrm{m}$ dense coating.

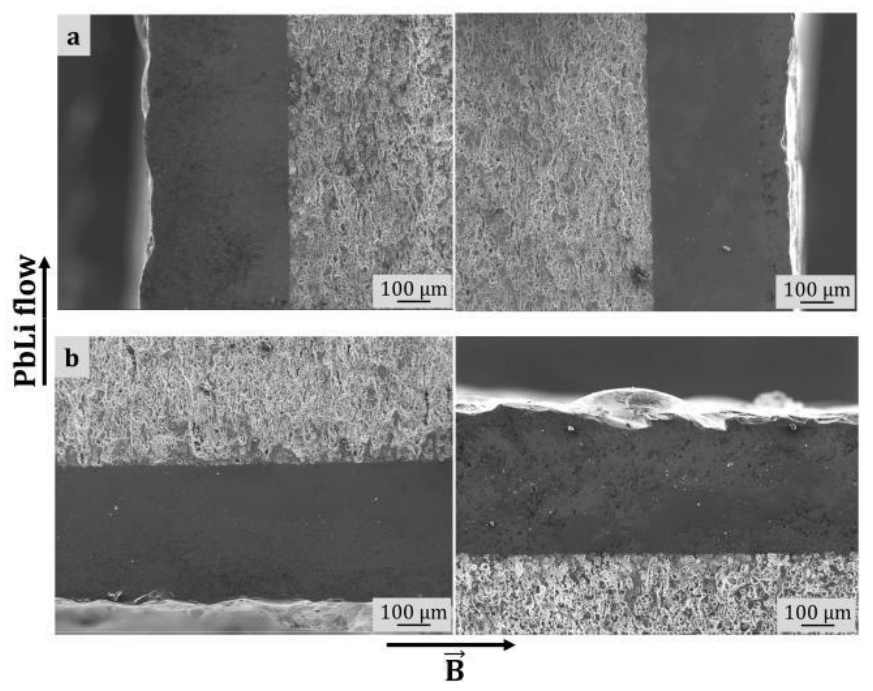

Fig. 15. Cross-sectional FEGSEM micrographs of the inside of a sample after the corrosion test under flowing PbLi; sample subjected to a magnetic field of $1.8 \mathrm{~T}$ throughout it, being (a) Hartmann walls and (b) side walls. Dense coating of $\sim 400 \mu \mathrm{m}$ thick.

the experiment. The surface was examined by FEGSEM and EDS analysis were performed, confirming that no $\mathrm{Pb}$ was present in the zones without dense coating. The reason for these detachments is unknown; severe temperature changes could have affected the integrity of some dense coatings during their extraction of the test assembly, or other followed procedures could have caused damages in the samples. More work is required to identify the problem and to assure that these conditions would not be repeated in service.

During the test, no failure happened in any case, and no weight gain was observed in any of the samples. Micrographs of the inside of a sample that remained outside the magnetic field can be seen in Fig. 14; no cracks or failures were detected in the dense coating, which provided protection against $\mathrm{PbLi}$ ingress. Likewise, micrographs of a sample subjected to the magnetic field are shown in Fig. 15. As can be observed, no substantial differences were found between the Hartmann and side walls, remaining the whole dense coating undamaged also in this series of samples.

\section{CONCLUSION}

The following conclusions can be drawn from the presented results.

1) Porous $\mathrm{SiC}$ with a variety of properties can be produced by the procedure followed in this paper, being possible to adjust the porosity according to the required needs. A $\mathrm{SiC}$ material with reduced thermal and electrical conductivities and sufficient mechanical strength can be fabricated by adding the required amount of sacrificial carbon phase.

2) A fully dense, free of defects CVD-SiC coating offers a reliable protection against hot $\mathrm{PbLi}$ corrosion. No remarkable effect of the application of a magnetic field on the corrosion behavior has been observed.

3) The gel-casting method is a promising route for the fabrication of ceramic for FCIs.

\section{ACKNOWLEDGMENT}

This work has been carried out within the framework of the EUROfusion Consortium. The views and opinions expressed herein do not necessarily reflect those of the European Commission.

\section{REFERENCES}

[1] L. V. Boccaccini et al., "Objectives and status of EURO fusion DEMO blanket studies," Fusion Eng. Des., vols. 109-111, pp. 1199-1206, Nov. 2016.

[2] D. Rapisarda et al., "Status of the engineering activities carried out on the European DCLL," Fusion Eng. Des., vol. 124, pp. 876-881, Nov. 2017.

[3] W. Krauss, S.-E. Wulf, and J. Konys, "Long-term corrosion behavior of ODS-Eurofer in flowing $\mathrm{Pb}-15.7 \mathrm{Li}$ at $550{ }^{\circ} \mathrm{C}$," Nucl. Mater. Energy, vol. 14, pp. 512-518, Dec. 2016.

[4] S. Smolentsev, S. Saedi, S. Malang, and M. Abdou, "Numerical study of corrosion of ferritic/martensitic steels in the flowing $\mathrm{PbLi}$ with and without a magnetic field," J. Nucl. Mater., vol. 432, nos. 1-3, pp. 294-304, 2013.

[5] M. C. Gázquez, T. Hernández, F. Muktepavela, E. Platacis, and A. Shishko, "Magnetic field effect on the corrosion processes at the Eurofer-Pb-17Li flow interface," J. Nucl. Mater., vol. 465, pp. 633-639, Oct. 2015.

[6] E. Platacis et al., "Investigation of the Li-Pb flow corrosion attack on the surface of P91 steel in the presence of magnetic field," Magnetohydrodynamics, vol. 48, no. 2, pp. 343-350, 2012.

[7] M. Abdou et al., "Blanket/first wall challenges and required R\&D on the pathway to DEMO,” Fusion Eng. Des., vol. 100, pp. 2-43, Nov. 2015. 
[8] S. Smolentsev, N. B. Morley, M. A. Abdou, and S. Malang, "Dualcoolant lead-lithium (DCLL) blanket status and R\&D needs," Fusion Eng. Des., vol. 100, pp. 44-54, Nov. 2015.

[9] L. Chen, M. Li, M. Ni, and N. Zhang, "MHD effects and heat transfer analysis in magneto-thermo-fluid-structure coupled field in DCLL blanket," Int. Commun. Heat Mass Transf., vol. 84, pp. 110-120, May 2017.

[10] C. Soto, J. M. Martínez-Esnaola, and C. García-Rosales, "Thermomechanical analysis of a flow channel insert based on a $\mathrm{SiC}$-sandwich material concept," Nucl. Mater. Energy, vol. 7, pp. 5-11, May 2016.

[11] Y. Katoh et al., "Current status and recent research achievements in SiC/SiC composites," J. Nucl. Mater., vol. 455, nos. 1-3, pp. 387-397, 2014.

[12] S. Sharafat et al., "Development status of a SiC-foam based flow channel insert for a U.S.-ITER DCLL TBM," Fusion Sci. Technol., vol. 56, no. 2, pp. 883-891, 2009.

[13] S. Smolentsev, C. Courtessole, M. Abdou, S. Sharafat, S. Sahu, and T. Sketchley, "Numerical modeling of first experiments on PbLi MHD flows in a rectangular duct with foam-based $\mathrm{SiC}$ flow channel insert," Fusion Eng. Des., vol. 108, pp. 7-20, Oct. 2016.

[14] M. Gonzalez, D. Rapisarda, A. Ibarra, C. Courtessole, S. Smolentsev, and M. Abdou, "Material analyses of foam-based SiC FCI after dynamic testing in PbLi in MaPLE loop at UCLA," Fusion Eng. Des., vols. 109111, pp. 93-98, Nov. 2015.

[15] C. Soto et al., "SiC-based sandwich material for flow channel inserts in DCLL blankets: Manufacturing, characterization, corrosion tests," Fusion Eng. Des., vol. 124, pp. 958-963, Nov. 2017.

[16] A. R. Studart, U. T. Gonzenbach, E. Tervoort, and L. J. Gauckler, "Processing routes to macroporous ceramics: A review," J. Amer. Ceram. Soc., vol. 89, no. 6, pp. 1771-1789, 2006.

[17] I. Barin, O. Knacke, and O. Kubaschewski, Thermochemical Properties of Inorganic Substances, 2nd ed. Düseldorf, Germany: Springer, 1991.

[18] R. Gilissen, J. P. Erauw, A. Smolders, E. Vanswijgenhoven, and J. Luyten, "Gelcasting, a near net shape technique," Mater. Des., vol. 21, no. 4, pp. 251-257, 2000.

[19] J. Yang, J. Yu, and Y. Huang, "Recent developments in gelcasting of ceramics," J. Eur. Ceram. Soc., vol. 31, no. 14, pp. 2569-2591, 2011.

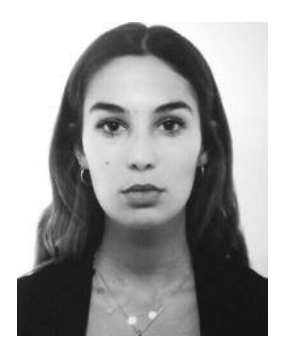

Carlota Soto received the M.Sc. degree in aerospace engineering from the Polytechnic University of Madrid, Madrid, Spain, in 2014. She is currently pursuing the Ph.D. degree with the Ceit-IK4 Tech-nology Center, San Sebastian, Spain. Her Ph.D. thesis topic on development and characterization of a SiC-based material, analyzing its application in high-temperature flow channel inserts.

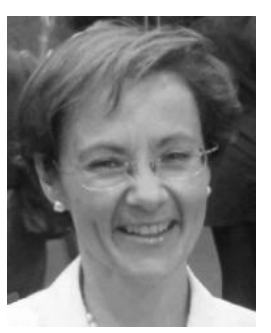

Carmen García-Rosales received the Degree in physics from the University of Muenster, Münster, Germany, in 1987. She completed her Ph.D. thesis at the Technical University Aachen, Aachen, Germany, in 1991.

She held a post-doctoral position at the PlasmaWall-Interaction Division, Max-Planck-Institute for Plasma Physics, Garching, Germany, from 1991 to 1993, where she was a Staff Scientist of fusion experiment ASDEX-Upgrade from 1993 to 1995. Since 1996, she has been a Scientist at the Ceit-

IK4 Technology Center, San Sebastian, Spain. Since 2012, she has been a Full Professor of solid state physics with the School of Engineering Tecnun, University of Navarra, Pamplona, Spain. Her current research interests include development of materials for nuclear fusion application, especially tungsten alloys, SiC-based materials, ODS steels, and doped carbon-based materials, using mainly powder metallurgical routes.

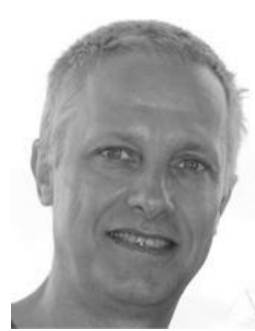

Jon Echeberria received the B.S. and M.S. degrees in chemistry from the University of the Basque Country, Leioa, Spain, in 1985, the Ph.D. degree in physics from the University of Navarra, Pamplona, Spain, in 1993. $\mathrm{He}$ joined the Materials Department, CEIT, Donostia/San Sebastián, Spain, in 1986. He is currently a Research Scientist with the Advanced Powder Metallurgy and Laser Manufacturing Group, Materials and Manufacturing Division, CEIT. He is also the Director of the Laboratory of Electron Microscopy, CEIT. He is an Associate Lecturer of

material science with Tecnun University of Navarra, San Sebastián. He has participated and supervised several National and European research projects, both through public calls and direct contracts with industrial companies. He is a Specialist in advanced ceramic processing: powder preparation (milling, mixing, kneading, and colloidal suspensions), forming (pressing, extrusion, slip-casting, dip-coating, and gel-casting), sintering (pressureless sintering, hot-pressing, hot-isostatic-pressing, and spark-plasma-sintering) and in microstructural characterization (in particular in nanometric and nanocrystalline materials) by SEM, FESEM, AFM, Dual Beam FIB/SEM, and TEM.

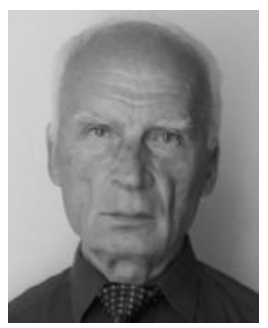

Ernests Platacis was born in Latvia in 1942. He received the Candidate of Technical Sciences degree from the Moscow Power Engineering Insti-tute, Moscow, Russia, in 1983, and the Ph.D. degree from the Academy of Sciences of Latvia, Riga, Latvia, in 1992.

From 1968 to 1983 , he set up the first research devoted to liquid metal control systems of reactivity (power) of nuclear reactors with the Nuclear Reactor of Institute of Physics Academy of Science, Latvia. Since 1983, he has been involved in magneto hydro-

dynamics technology. He has made important contribution to the development of high-temperature electromagnetic pumps for cooling systems of nuclear space reactors. These activities have been performed in close cooperation with experimental studies carried out in the company energy and other research centers in the former USSR. In 1996, he became the Head of the Physical Hydro Mechanic Laboratory, Institute of Physics. His activities has been involved in science focusing on the developing and investigation of magnetohydrodynamic machines and elements (electromagnetic pumps, flow meters, and level meters) as well as studies related to the behavior of structural materials (stainless steel, Eurofer, and P-91) in liquid metal, and magnetic field at the relatively high temperatures (up to $700^{\circ} \mathrm{C}$ ).

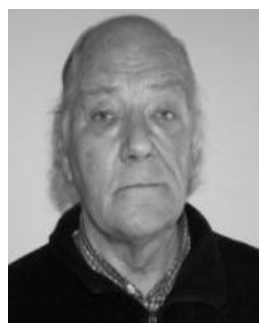

Andrejs Shisko was born in Latvia in 1945. He received the Candidate of Technical Sciences degree from the St.-Petersburg Polytechnical Institute, Saint Petersburg, Russia, in 1979, and the Ph.D. degree from the Latvian Academy of Sciences, Riga, Latvia, in 1992.

Since 1969, he has been with the Institute of Physics, University of Latvia, Riga. From 1969 to 1988, he was involved in the investigations of electrodynamic processes in magnetohydrodynamic (MHD) channels at large magnetic Reynolds numbers. Since 1988, his main activities are concerned with the investigation of MHD processes under fusion reactor conditions and with the effect of strong magnetic fields on steel (e.g., EUROFER) corrosion phenomena in liquid metals flows. Until 1990, he involved in close cooperation with the St.Petersburg Research Institute of Electro-Physical Apparatus, Saint Petersburg. 


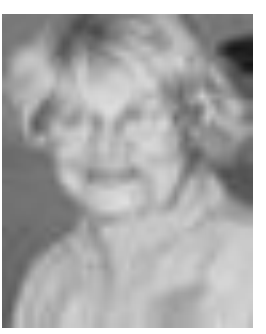

Faina Muktepavela received the B.S and M.Sc. degrees in physics of metals from the University of Metals and Allojs, Moscow, Russia, in 1967, and the $\mathrm{Ph} . \mathrm{D}$. degree in physics from the Institute of Physics, Latvian Academy of Sciences, Riga, Latvia, in 1980. From 1967 to 1968, she was a Researcher with the Institute of Radioizotope Devices in Riga, and from 1968 to 1993 , she was a Senior Researcher with the Institute of Physics, Latvian Academy of Sciences, where her research interests were in the field of atomically clean surfaces, adhesion, superplasticity,

and nanohardness of solids metals, and also magnetohydrodynamic effects in the flow of metals. Since 1993, she has been a Leading Researcher with the Institute of Solid State Physics, University of Latvia, Riga, where her research topics are structure and properties of grain boundaries and interfaces in functional nanostructured materials (ceramics; metals, thin films, and sintering effects) and also corrosion, wetting, and brittleness problems in nuclear materials.

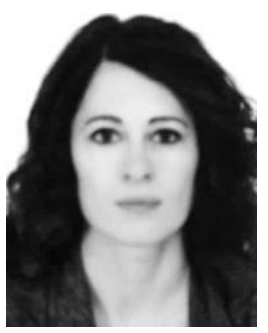

Teresa Hernández received the Chemist degree from the Universidad Complutense de Madrid, Madrid, Spain, in 1986, and the Ph.D. degree from the Ceramic and Glass Institute, Consejo Superior de Investigaciones Científicas, Madrid, in 1990, where she was involved in the synthesis and development of fast ions conductors for fuel cells applications.

Since 1992, she has been a Scientist with the Fusion Technology Division, Centro de Investigaciones Energéticas, Medioambientales y Tecnológicas, Madrid, with a focus on the study of dielectrics

for fusion and the irradiation effects. She has authored over 50 scientific papers related to fusion materials and is a member of some European scientific committees and groups specialized in materials science. She has participated in over 25 research projects, being the Supervisor of two international chapters. Her current research interests include corrosion and compatibility studies of liquid metal related to fusion reactors, research and development of physical properties of $\mathrm{SiC}$ and $\mathrm{SiC} / \mathrm{SIC}$ composites and ceramics related to fusion reactors, and fusion reactors materials and radiation damage.

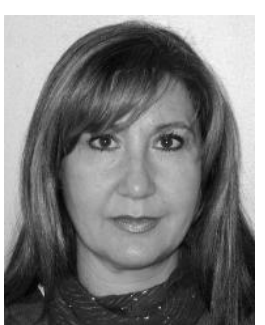

Marta Malo Huerta received the Ph.D. degree in physics from the Universidad Complutense de Madrid, Madrid, Spain, in 2014.

She is a Researcher with the National Fusion Laboratory, Centro de Investigaciones Energéticas, Medioambientales y Tecnológicas, Madrid, with a specialization in radiation damage in materials and systems for fusion applications. She has ten years of experience in irradiation facilities. Her participation in advanced studies focused on the characterization of the radiation effects in optical and electrical

properties of ceramic materials for diagnostics and heating and current drive applications in future fusion devices within european (EUROfusion, Fusion for Energy) and international (Broader Approach) projects framework. 